Tohoku J. exp. Med., 1982, 138, 177-185

\title{
Further Observation on Empyema after Resection of Bronchogenic Carcinoma and Survival
}

\author{
Kazuo Sekiguchi \\ The Division of Thoracic Surgery, the Seirei Hospital, 3453 \\ Mikatabara, Hamamatsu 433
}

\begin{abstract}
SeKiguchi, K. Further Observation on Empyema after Resection of Bronchogenic Carcinoma and Survival. Tohoku J. exp. Med., 1982, 138 (2), 177-185 Out of 11,247 cases undergoing resectional therapy for bronchogenic carcioma at 39 institutions, 6,348 were operated before July 1976 and the remaining 4,899 thereafter. Analyzing both series, the following results were obtained: 1) The rate of pneumonectomies to lobectomies was $1: 2.3$ in the former and $1: 3.9$ in the latter. Pneumonectomies were more on the left side, whereas the right lobectomies were about twice as many as the left ones. 2) Postoperative empyema occurred in 180 cases $(2.8 \%)$ in the former and 79 cases $(1.6 \%)$ in the latter. The incidence was significantly higher in the cases of right pneumonectomy than in the cases of left pneumonectomy, and in the cases of pneumonectomy than in the cases of lobectomy. Although the incidence of postpneumonectomic empyema decreased only slightly, overall incidence decreased significantly because of marked increase of lobectomy cases. 3) Out of 180 cases of empyema in the former series, 17 died within 30 days. 4) The 5-year survival rate of the patients with empyema was 28 per cent. 5) The 5-year survival rate was 30 per cent in 93 cases of squamous cell carcinoma, 30 per cent in 50 cases of adenocarcinoma and 15 per cent in 13 cases of large cell carcinoma. There was no survivor among 7 cases of small cell carcinoma. 6) Out of 259 cases of empyema, micro-organisms were cultured in 161 cases, were negative in 20, and unknown in 78. Although various organisms were found, gram-negative bacteria and Pseudomonas were most frequently isolated, i.e. 37 per cent and 36 per cent, respectively. 7) As for the treatment of 5-year survival cases of empyema, thoracoplasty and bronchial closure were frequent as compared with open thoracic window technics such as Eloesser's and Symbas' operation. And, more than half of the cases of empyema seem to have been complicated with bronchial fistulae. - ....... pneumonectomy; lobectomy; postoperative empyema; bronchogenic carcinoma; survival rate
\end{abstract}

In 1976 the first cooperative study was performed to examine the results of patients with postoperative empyema. By analysing 6,349 cases of pulmonary resection at 48 institutions up to 1975 , the following results were obtained: 1) The rate of pneumonectomies to lobectomies was $1: 2.5$ and pneumonectomies were more on the left side, whereas the right lobectomies were about twice as many as the left ones. Empyema occurred in 178 cases $(2.8 \%)$. The incidence was significantly higher in the cases of pneumonectomy than in the cases of lobectomy, and in the cases of right pneumonectomy than in the cases of left one. Out of 114 patients with empyema before 1971, 15 died within 30 days. The 5-year

Received for publication, February 4, 1982. 
survival rate was 35 per cent in the 96 cases of empyema, but 15 of hospital death and 3 of unknown TNM classification.

As the cases of pneumonectomy for bronchogenic carcinoma seem to be decreasing, the present study was undertaken to ascertain the recent incidence of postoperative empyema and to analyze organisms from empyema cavities.

\section{Patients And Methods}

Inquring further cases to 48 institutions which had participated in the former study, 4,899 cases of bronchogenic carcinoma were collected from 39 institutions, 79 of which were complicated with postoperative empyema. One institute excluded 7 from 17 cases which had been reported as those of empyema, and another corrected the diagnosis in one case of small cell cacrinoma to carcinoid. Therefore, the number of patients operated before July 1976 and that of patients with empyema were 6,348 and 180 , respectively. As for the classification of curability, one institute had reported all cases as curative, and another as noncurative in the former period, but both divided cases into three groups in the later period. The other three had divided cases into curative and noncurative operation groups, but later one of them divided cases into three groups. In addition, some institutions reported that several cases formerly judged as curative were reestimated as semicurative unless complete dissection was performed, or the former classification was more or less altered, since systemic dissection was not carried out before 1977. Even the data of other institutions seem to have been changed to some extent. Nevertheless, data from these institutions were analyzed according to their original descriptions.

\section{RESULTS}

The collected cases are summarised in Table 1. The upper and lower rows indicate the number of patients operated before July 1976 and thereafter, respectively. In the same way as the former report, pneumonectomies were more on the left side, whereas the right lobectomies were about twice as many as the left ones. As a whole, the incidence of pneumonectomy cases decreased from 30 per cent to 20 .

Empyema occurred in 180 cases $(2.8 \%)$ of the former series and 79 cases $(1.6 \%)$

TABLE 1. Summary of the collected cases

\begin{tabular}{lrrrr} 
& \multicolumn{4}{c}{ Number of cases } \\
\cline { 2 - 3 } & \multicolumn{1}{c}{ Curative } & Semicurative & Noncurative & \multicolumn{1}{c}{ Total } \\
\cline { 5 - 5 } Right pneumonectomy & $195(7.8)$ & $173(12.5)$ & $394(16.3)$ & $762(12.0)$ \\
& $95(4.7)$ & $137(9.9)$ & $159(10.8)$ & $391(8.0)$ \\
Left pneumonectomy & $299(11.7)$ & $291(21.0)$ & $522(21.6)$ & $1,112(17.5)$ \\
& $185(9.1)$ & $181(13.1)$ & $235(15.9)$ & $601(12.3)$ \\
Right lobectomy & $1,380(54.1)$ & $609(44.0)$ & $988(40.9)$ & $2,977(46.9)$ \\
Left lobectomy & $1,071(52.4)$ & $647(46.9)$ & $702(47.6)$ & $2,420(49.4)$ \\
& $675(26.5)$ & $310(22.4)$ & $512(21.2)$ & $1,497(23.6)$ \\
Total & $693(33.9)$ & $416(30.1)$ & $378(25.6)$ & $1,487(30.4)$ \\
& $2,549(40.2)$ & $1,383(21.8)$ & $2,416(38.1)$ & $6,348(100)$ \\
& $2,044(41.7)$ & $1,381(28.2)$ & $1,474(30.1)$ & $4,899(100)$
\end{tabular}

Upper row: Number of cases resected before July 1976.

Lower row: Number of cases resected after August 1976. 
of the latter series (Table 2). The incidence was significantly higher in the cases of right pneumonectomy than in the cases of left one and in the cases of pneumonectomy than in the cases of lobectomy. Although the incidence of postpneumonectomic empyema decreased only slightly, the overall incidence decreased significantly.

TABLE 2. Incidence of postoperative empyema

\begin{tabular}{|c|c|c|c|c|}
\hline & Curative & $\begin{array}{l}\text { Number of cas } \\
\text { Semicurative }\end{array}$ & $\begin{array}{l}\text { and incidence } \\
\text { Noncurative }\end{array}$ & Total \\
\hline \multirow{3}{*}{ Right pneumonectomy } & $\%$ & $\%$ & $\%$ & $\%$ \\
\hline & $4(2.1)$ & $8(4.6)$ & $37(9.4)$ & $49(6.4)$ \\
\hline & $1(1.1)$ & $2(1.5)$ & $12(7.5)$ & $15(3.8)$ \\
\hline \multirow[t]{2}{*}{ Left pneumonectomy } & $13(4.4)$ & $8(2.8)$ & $13(2.5)$ & $34(3.1)$ \\
\hline & $3(1.6)$ & $6(3.3)$ & $9(3.8)$ & $18(3.0)$ \\
\hline \multirow[t]{2}{*}{ Right lobectomy } & $35(2.5)$ & $14(2.3)$ & $22(2.2)$ & $71(2.4)$ \\
\hline & $14(1.3)$ & $13(2.0)$ & $8(1.1)$ & $35(1.5)$ \\
\hline \multirow[t]{2}{*}{ Left lobectomy } & $7(1.0)$ & $5(1.6)$ & $14(2.7)$ & $26(1.7)$ \\
\hline & $6(0.9)$ & $4(1.0)$ & $1(0.3)$ & $11(0.7)$ \\
\hline \multirow[t]{2}{*}{ Total } & $59(2.3)$ & $35(2.5)$ & $86(3.6)$ & $180(2.8)$ \\
\hline & $24(1.2)$ & $25(1.8)$ & $30(2.0)$ & $79(1.6)$ \\
\hline \multirow[t]{2}{*}{ Pneumonectomy } & $17(3.4)$ & $16(3.5)$ & $50(5.5)$ & $83(4.4)$ \\
\hline & $4(1.4)$ & $8(2.5)$ & $21(5.3)$ & $33(3.3)$ \\
\hline \multirow[t]{2}{*}{ Lobectomy } & $42(2.0)$ & $19(2.1)$ & $36(2.4)$ & $97(2.2)$ \\
\hline & $20(1.1)$ & $17(1.6)$ & $9(0.8)$ & $46(1.2)$ \\
\hline \multirow[t]{2}{*}{ Right side } & $39(2.5)$ & $22(2.8)$ & $59(4.3)$ & $120(3.2)$ \\
\hline & $15(1.3)$ & $15(1.9)$ & $20(2.3)$ & $50(1.8)$ \\
\hline \multirow[t]{2}{*}{ Left side } & $20(2.1)$ & $13(2.2)$ & $27(2.6)$ & $60(2.3)$ \\
\hline & $9(1.0)$ & $10(1.7)$ & $10(1.6)$ & $29(1.4)$ \\
\hline
\end{tabular}

Upper row: Number of cases of empyema before July 1976.

Lower row: Number of cases of empyema after August 1976.

Hospital death was observed in $14(12.5 \%)$ of 112 patients with empyema before December 1971 and in $3(4.4 \%)$ of 68 cases of empyema from January 1972 to July 1976. Five-year survival rates of these series excluding the cases of hospital death were 31 per cent and 23 per cent, respectively. Table 3 represents the 5year survival rate in each clinical stage and grade of curability.

The 5-year survival rate in each histopathologic type is shown in Table 4. Out of 163 cases, 93 were diagnosed as squamous cell carcinoma, 50 as adenocarcinoma, 13 as large cell carcinoma and 7 as small cell carcinoma. The 5year survival rates of these groups were 30 per cent, 30 per cent, 15 per cent and nil, respectively.

Of 180 cases of empyema in the former series microorganisms were cultured in 95 cases, were negative in 15 , and unknown in 70 . Of 79 cases in the latter series 66 were positive, 5 negative, and 8 unknown. Dividing the microorganisms into 8 groups, that is 1) Pseudomonas, 2) Staphylococcus aureus, 3) Streptococcus hemolyticus, 4) gram-positive cocci, 5) gram-negative bacteria (Escherichia coli, Klebsiella, Proteus, etc.), 6) nonpathologic streptococci (Streptococcus viridans, Streptococcus fecalis, nonhemolytic and anaerobic), 7) nonpathologic bacteria (Bacteroides, Diphtheroids, Micrococcus, gram-positive bacteria, Corynebacterium, etc.) and 8) 

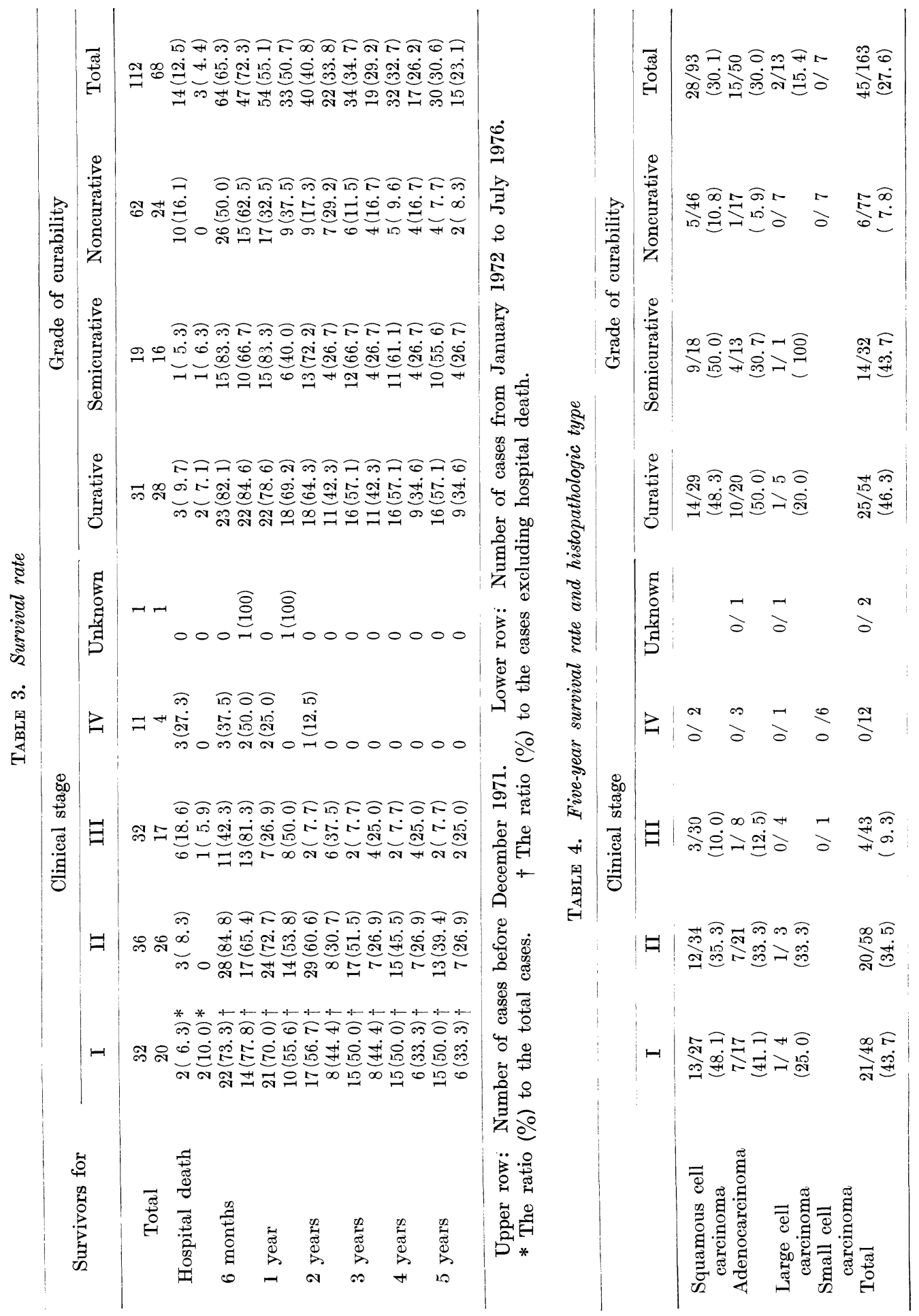
TABLE 5. Microorganisms isolated from the empyema cavities

\begin{tabular}{lccc}
\hline & $\begin{array}{c}\text { Cases positive } \\
\text { in culture }\end{array}$ & $\begin{array}{c}\text { Cases of empyema } \\
\text { before July 1976 }\end{array}$ & $\begin{array}{c}\text { Cases which survived } \\
\text { more than 5 years }\end{array}$ \\
\hline Total & 161 & 95 & 27 \\
Pseudomonas & $58(36.0)$ & $32(33.7)$ & $7(25.9)$ \\
Staphylococcus aureus & $22(13.7)$ & $16(16.8)$ & $5(18.5)$ \\
Streptococcus hemolyticus & $12(7.5)$ & $5(5.3)$ & $2(7.4)$ \\
Gram-positive cocci & $9(5.6)$ & $4(4.2)$ & $2(7.4)$ \\
Gram-negative bacteria & $60(37.3)$ & $42(44.2)$ & $8(29.6)$ \\
Nonpathologic streptococci & $9(5.6)$ & $6(6.3)$ & $3(11.1)$ \\
Nonpathologic bacteria & $20(12.4)$ & $17(17.9)$ & $4(14.8)$ \\
Other organisms & $29(18.0)$ & $20(21.1)$ & $6(22.2)$ \\
\hline
\end{tabular}

TABLE 6. Adjuvant therapy in 163 patients with empyema in the former series

\begin{tabular}{|c|c|c|c|c|c|}
\hline Clinical stage & Chemotherapy & Radiation & $\begin{array}{l}\text { Chemotherapy } \\
\& \text { radiation }\end{array}$ & None & Total \\
\hline Survivors & $18(40.0)$ & $10(22.2)$ & $6(13.3)$ & $11(24.4)$ & $45(27.5)$ \\
\hline I \& II & $26(39.0)$ & $9(22.2)$ & $6(14.6)$ & $10(24.4)$ & $41(91.1)$ \\
\hline III \& IV & $2(50.0)$ & $1(25.0)$ & 0 & $1(25.0)$ & $4(8.9)$ \\
\hline Non-survivors & $44(37.3)$ & [9 $(16.1)$ & $17(14.4)$ & $38(32.2)$ & $118(72.4)$ \\
\hline I \& II & $27(42.2)$ & $9(14.1)$ & $8(12.5)$ & $20(31.2)$ & $64(54.2)$ \\
\hline III \& IV & $17(32.7)$ & $10(19.2)$ & $8(15.4)$ & $17(32.7)$ & $52(44.1)$ \\
\hline Unknown & 0 & 0 & $1(50.0)$ & $1(50.0)$ & $2(100)$ \\
\hline Total & $62(38.0)$ & $29(17.8)$ & $23(14.1)$ & $49(30.1)$ & $163(100)$ \\
\hline
\end{tabular}

TABLE 7. Treatment of 180 cases of empyema in the former series

\begin{tabular}{lllllllr} 
& Antibiotics & Drainage Thoracoplasty & $\begin{array}{c}\text { Closure of } \\
\text { fistulae }\end{array}$ & Resection & $\begin{array}{c}\text { Eloesser's } \\
\text { operation }\end{array}$ & Total \\
\hline $\begin{array}{l}\text { Died within } \\
\text { 1 year }\end{array}$ & $34(36.9)$ & $22(23.9)$ & $19(20.6)$ & $9(9.9)$ & $2(2.2)$ & $6(6.5)$ & $\begin{array}{r}(100) \\
92(51.1) \\
(100)\end{array}$ \\
$\begin{array}{l}\text { Died after } \\
\quad \text { 1-5 years }\end{array}$ & $10(23.3)$ & $15(34.9)$ & $6(13.9)$ & $3(7.0)$ & $4(9.3)$ & $5(11.6)$ & $43(23.9)$ \\
$\begin{array}{c}\text { Alive for more } \\
\text { than 5 years }\end{array}$ & $10(22.2)$ & $16(35.6)$ & $10(22.2)$ & $7(15.6)$ & 0 & $2(4.4)$ & $45(25.0)$ \\
Total & $54(30.0)$ & $53(29.4)$ & $35(19.4)$ & $19(10.6)$ & $6(3.3)$ & $13(7.2)$ & $180(100)$ \\
\hline
\end{tabular}

other organisms, it was found that gram-negative bacteria, Pseudomonas and other organisms were most frequently isolated as shown in Table 5.

Adjuvant therapy in 163 of the 180 patients is listed in Table 6 . Seventeen cases of hospital death were excluded. There was no significant difference between 5-year-survivors and non-survivors.

The treatment of these patients is shown in Table 7 . When 45 survivors are compared with 43 non-survivors except for 92 cases of death within one year, some differences are noted. That is, 5-year survivors had a high incidence of thoracoplasty and bronchial closure in contrast to a low incidence of open thoracic window technics such as Eloesser's and Symbas' operation and received no second resection. The treatment in 79 cases of empyema in the latter series is shown in Table 8. 
TABLE 8. Treatment of 79 cases of empyema in the latter series

\begin{tabular}{|c|c|c|c|c|c|c|c|}
\hline & Antibiotics & Drainage & Thoracoplasty & $\begin{array}{l}\text { Closure of } \\
\text { fistulae }\end{array}$ & Resection & $\begin{array}{l}\text { Eloesser's } \\
\text { operation }\end{array}$ & Total \\
\hline Died within & & & & & & & $(100)$ \\
\hline $\begin{array}{l}1 \text { year after } \\
\text { operation }\end{array}$ & $2(6.1)$ & $20(60.6)$ & $1(3.0)$ & $2(6.1)$ & $2(6.1)$ & $6(18.1)$ & $33(41.8)$ \\
\hline $\begin{array}{l}\text { Alive for less } \\
\text { than } 1 \text { year* }\end{array}$ & $1(9.1)$ & $6(54.5)$ & $2(18.2)$ & 0 & 0 & $2(18.2)$ & $\begin{array}{r}(100) \\
11(13.9)\end{array}$ \\
\hline Died 1-4 years & (1) & $0(07.0)$ & $2(10.07$ & 0 & 0 & $4(10.21$ & $(100)$ \\
\hline $\begin{array}{l}\text { after opera- } \\
\text { tion }\end{array}$ & $1(7.7)$ & $6(46.1)$ & $4(30.8)$ & 0 & $2(15.4)$ & 0 & $13(16.5)$ \\
\hline Alive for & & & & & & & ( 100$)$ \\
\hline 1-5 years & $3(13.6)$ & $6(27.3)$ & $7(31.8)$ & $4(18.2)$ & 0 & $2(9.1)$ & $22(27.8)$ \\
\hline Total & $7(8.9)$ & $38(48.1)$ & $14(17.7)$ & $6(7.6)$ & $4(5.1)$ & $10(12.6)$ & $79(100)$ \\
\hline
\end{tabular}

* The cases alive at the time of this study less than 1 year after operation.

Comparing 22 cases surviving 1 to 5 years after resection with 13 cases of death within 1 to 4 years, the cases treated by bronchial closure or open thoracic window technics are found only in the survivors, and the cases which received the second resection are present only in the non-survivors.

\section{Discussion}

The incidence of pnuemonectomy cases was as high as 29 per cent of the 6,349 cases in the fomer report (Sekiguchi et al. 1979). Recently, much attention has been paid for limited operation, although extended operation has been performed on the other hand. The present study revealed that the incidence of pneumonectomy cases decreased remarkably as expected.

The incidence of postoperative empyema was significantly higher in the cases of pneumonectomy than in the cases of lobectomy as reported previously. Therefore, it is easily supposed that the overall incidence of postoperative empyema may decrease as far as the number of pneumonectomy cases decrease. Comparing the data of both periods, the incidence of postlobectomic empyema decreased remarkably, although that of postpneumonectomic empyema decreased only slightly. The postpneumonectomic empyema may be caused by frequent application of extended operation.

As compared with the incidence (14 per cent) of hospital death in the previous report, the incidence (9 per cent) in the present study is low. On the other hand, the 5-year survival rate decreased from 35 per cent to 28 per cent. However, there are no significant differences between these figures.

Since more than half of the cases died within one year, complication of empyema is apparently the main cause of death. If the patients, especially those who received curative and semicurative operation or those in I and II clinical stages, could survive the complication, nonspecific immunocompetent activity caused by the infected bacteria might prolong their survival time. This may be true for the 
early cases which had never received adjuvant therapy or had been treated only by radiation, but not for the recent cases which have been receiving immunotherapy. Decline of the survival rate in the later period may be explained by this reason.

Takita (1970) reported that postoperative empyema was observed in 14 cases $(7 \%), 7$ of which survived more than 5 years, and Staphylococcus was the most common organism in both 5-year survivors and non-survivors. Ruckdeschel et al. (1972) also reported that organisms isolated from the empyema cavities included Staphylococcus aureus, Escherichia coli, Pseudomonas aeruginosa and Candida albicans, and these organisms were equally represented among the long-term and short-term survivors in the empyema group. They stated that other nonimmune mechanisms may be involved such as physical blockade of the pleural lymphatics by the inflammatory process or production of tumoricidal products by the bacterial organisms, as Coley (1906) postulated. They considered that during the interaction of immune lymphocytes with empyema organisms two major nonspecific and effective mechanisms, lymphokines and "angry macrophages", were activated within the chest. Finally, they considered this nonspecific component of the host response to be responsible for the prolongation of survival.

Sensenig et al. (1963) also pointed out that in view of the experimental evidence that both gram-positive and gram-negative bacteria produce antitumor substances, this subject bears additional investigation.

Cady and Cliffton (1967) stated that when a few 5-year survivors were compared with non-survivors, several interesting differences were noted. That is, the survivors had more infection with Staphylococcus aureus and Streptococccus hemolyticus, a large number of organisms per infection, and fewer infections with single organism. Evidence is offered that the increased incidence of staphylococcal and hemolytic streptococcal infections noted in long-term survivors in the present study is probably related to enhanced host resistance factors.

Since Halpern et al. (1964) reported the influence of Corynebacterium parvum on the reticuloendothelial system and the possibility of tumoricidal effect, its nonspecific immunocompetent action has been ascertained by many investigators.

Hattori and Mori $(1973 \mathrm{a}, \mathrm{b})$ found Corynebacterium liquefaciens from the marrow of the human sternum, but neither from that of the human ilium, nor peripheral venous blood. This microorganism was detected significantly less frequently in patients with carcinoma than in healthy persons and patients with benign diseases. They examined its tumoricidal effect and prepared heat-killed bacterium of $C$. liquefaciens isolated from the sternal marrow of the patients with bronchogenic carcinoma, but this was not brought to clinical use. As for preparation of hemolytic streptococci, OK-432 produced by Okamoto et al. (1967) has been already used clinically.

From the background mentioned above, it seems very important to elucidate organisms in the cases of empyema. But unfortunately, organisms were found in only 42 per cent of 259 cases of empyema. In addition, species were not determined in about half of the cases. As for anaerobic bacteria, only two cases were reported. 
Therefore, organisms from the empyema cavities were compared by dividing them into 8 groups, and gram-negative bacteria, Pseudomonas and other organisms were most frequent. If anaerobic bacteria were examined routinely, the frequency of nonpathologic bacteria including Corynebacteria might be raised. The incidences of hemolytic streptococci and Serratia were only 7 per cent and 4 per cent, respectively.

The present study revealed 4 cases of empyema after limited operation. As it was impossible to calculate the number of cases which received either extended or limited operation, exact incidences of the cases of empyema following the two operations were unknown. Some institutions might have included cases of segmentectomy or wedge resection in those of lobectomy.

In spite of the recent advances in the field of immunotherapy, there were only 2 cases combined with immunotherapy in 189 cases of the former series and 22 in 79 cases of the latter series. Accordingly, no significant relationship was observed between the cases alive more than 1 year and those of death within 1 year in regard to adjuvant therapy for lung cancer.

Cases of empyema vary from those which are relatively easily controlled by antibotics with or without puncture to those which are severely complicated by bronchial fistulae. Most of the cases of death within 1 year are considered to be those which failed in the treatment of empyema. As for the cases which survived more than one year, it seems likely that the 5-year-survivors had high incidence of thoracoplasty and bronchial closure, low incidence of open thoracic window technics and no second resection. However, this subject awaits further investigation.

The incidence of postoperative empyema and bronchial fistulae reported during the 1950's when resectional therapy for pulmonary tuberculosis was most frequent ranged from 3 to 5 per cent and from 5 to 7 per cent, respectively (Sekiguchi 1959). The incidence of postoperative empyema revealed by the present study is about the same as that in the surgical management of tuberculosis. Therefore, it is supposed that more than half of the cases of empyema might be associated with bronchial fistulae.

\section{Acknowledgment}

Thirty-nine Institutions participated in the cooperative study are: The Second Surgical Department, Hokkaido University; the Research Institute for Tuberculosis and Cancer, Tohoku University; the Department of Surgery, Keio University School of Medicine; the Surgical Department, Tokyo Medical College; the Lung Cancer Research Institute, Chiba University School of Medicine; the Second Surgical Department, Niigata University School of Medicine; the Second Surgical Department, Nagoya University School of Medicine; the Second Surgical Department, Nagoya Municipal University School of Medicine; the Department of Thoracic Surgery, Mie University School of Medicine; the Research Institute of Chest Diseases, Kyoto University School of Medicine; the Department of Thoracic Surgery, Kansai Medical College; the First Surgical Department, Osaka University School of Medicine; the Second Surgical Department, Kobe University School of Medicine; the Second Surgical Department, Tokushima University School of Medicine; the First Surgical Department, Nagasaki University School of Medicine; the First Surgical 
Department, Kagoshima University School of Medicine; the Saitama Cancer Center Hospital; the National Cancer Center Hospital; the Surgical Department, Cancer Reserch Institute; the Chiba Cancer Center Hospital; the Aichi Cancer Center Hosptial; Center for Adult Diseases, Osaka; the Kyushu Cancer Center Hospital; the National Sanatorium Dohoku Hospital; the National Sanatoriun Tokyo Hospital; the National Sanatorium Nakano Hospital; the National Sanatorium Kinki Hospital; the National Sanatorium Toneyama Hospital; the National Sanatorium Sanyoso Hospital; the National Sanatorium Saishunso Hospital; the Tokyo Teishin Hospital; the Central Hosptial of the Japanese National Railways; the Tuberculosis Research Institute, Antituberculosis Association; the Iwaki Hospital; the Kawasaki City Ida Hospital; the Fujimi Hospital; the Seirei Hospital; the Tenri Yorozu Sodansho Hospital; the Kyoto Katsura Hospital.

\section{References}

1) Cady, B. \& Cliffton, E.E. (1967) Empyema and survival following surgery for bronchogenic carcinoma. J. thorac. cardiovasc. Surg., 53, 102-107.

2) Coley, W.B. (1906) Late results of the treatment of inoperable sarcoma by the mixed toxins of eryspielas and Bacillus prodigosus. Amer. J. med. Sci., 131, 375-430.

3) Halpern, B.N. Prevot, A.R., Biozzi, G., Mouton, D., Morard, J.C., Bouthillier, Y. \& Decreuselfond, C. (1964) Stimulation de l'activité phagocytaire du système réticuloendothérial provoquée par Corynebacterium parvum. J. Reticuloendothel. Soc., $1,77-96$.

4) Hattori, T. \& Mori, A. (1973a) Bacteriologial survey of anaerobic Corynebacterium in human bone marrow and blood. Gann, 64, 7-14.

5) Hattori, T. \& Mori, A. (1973b) Antitumor activity of anaerobic Corynebacterium isolated from the human bone marrow. Gann, 64, 15-27.

6) Okamoto, H., Shoin, S., Koshimura, S. \& Shimizu, R. (1967) Studies on the anticancer and streptolysin S-forming abilities of hemolytic streptococci. Jap. J. Microbiol., 11, $323-336$.

7) Ruckdeschel, D.C., Codish, S.D., Stranahan, A. \& McKneally, M.F. (1972) Postoperative empyema improves survival in lung cancer. New Engl. J. Med., 287, 1013-1017.

8) Sekiguchi, K. (1959) Pitfall of medical statistics with special reference to the complication of pulmonary resection. Kyobugeka, 12, 679-701. (Japanese)

9) Sekiguchi, K., Oki, S. \& Sugimoto, H. (1979) Influence of empyema after resection for bronchogenic carcinoma and survival (cooperative study in Japan). Tohoku J. exp. Med., 128, 63-69.

10) Sensenig, D.M., Rossi, N.P. \& Ehrenhaft, J.L. (1963) Results of the surgical treatment for bronchogenic carcinoma. Surg. Gynec. Obstet., 116, 279-284.

11) Takita, H. (1970) Effect of postoperative empyema on survival of bronchogenic carcinoma. J. thorac. cardiovasc. Surg., 59, 642-644. 